Int. J. Environ. Res. Public Health 2008, 5(2), 104-110

International Journal of

Environmental Research and Public Health

ISSN 1661-7827

www.ijerph.org

(c) 2008 by MDPI

\title{
Evaluation of the Effect of Ecologic on Root Knot Nematode, Meloidogyne incognita, and Tomato Plant, Lycopersicon esculenum
}

\author{
Debora C. Ladner ${ }^{1}$, Paul B. Tchounwou ${ }^{1 *}$ and Gary W. Lawrence ${ }^{2}$ \\ ${ }^{1}$ Environmental Toxicology Research Laboratory, College of Science, Engineering and Technology, Jackson State University, \\ Jackson, Mississippi 39217, USA \\ ${ }^{2}$ Department of Entomology and Plant Pathology, Mississippi State University, MS 39762, USA. \\ *Correspondence to Dr. Paul B. Tchounwou; Email: paul.b.tchounwou@jsums.edu
}

Received: 25 October 2007/ Accepted: 30 April 2008 / Published: 30 June 2008

\begin{abstract}
Nonchemical methods and strategies for nematode management including cultural methods and engineered measures have been recommended as an alternative to methyl bromide (a major soil fumigant), due to its role in the depletion of the ozone layer. Hence, an international agreement has recently been reached calling for its reduced consumption and complete phasing out. This present research evaluates the potential of Ecologic, a biological, marine shell meal chitin material, as a soil amendment management agent for root knot nematode, Meloidogyne incognita, control, and its effect on the growth of Floradel tomato plant, Lycopersicon esculentum. To accomplish this goal, studies were conducted during which, experimental pots were set up in greenhouse environments using sterilized soil inoculated with 5,000 root-knot eggs per $1500 \mathrm{~g}$ soil. There were 4 treatments and 5 replications. Treatments were: No chitin; 50 g chitin; $100 \mathrm{~g}$ chitin; and $200 \mathrm{~g}$ chitin. A two-week wait period following Ecologic amendment preceded Floradel tomato planting to allow breakdown of the chitin material into the soil. Fresh and dry weights of shoot and root materials were taken as growth end-points. A statistically significant difference $(p \leq 0.05)$ was obtained with regard to the growth rate of $L$. esculentum at $100 \mathrm{~g}$ chitin treatment compared to the control with no chitin. Mean fresh weights of Floradel tomato were $78.0 \pm 22.3 \mathrm{~g}, 81.0 \pm 20.3 \mathrm{~g}, 109.0 \pm 25.4 \mathrm{~g}$ and $102.0 \pm 33.3 \mathrm{~g}$ at $0,50,100$ and $200 \mathrm{~g}$ chitin, respectively. The analysis of root knot nematode concentrations indicated a substantial effect on reproduction rate associated with chitin amendment. Study results showed a significant decrease in both root knot nematode eggs and juveniles (J2) at 100g and 200g Ecologic chitin levels, however, an increase in nematode concentrations was recorded at the $50 \mathrm{~g}$ Ecologic chitin level $(\mathrm{p} \leq 0.05)$. The mean amounts of $\mathrm{J} 2$ population, as expressed per $1500 \mathrm{~cm}^{3}$ soil, were 49,933 \pm 38,819, 86,050 $\pm 25248,103 \pm 133$ and $103 \pm 133$ for $0,50,100$ and 200g chitin, respectively. Similarly, the mean numbers of root knot nematode eggs (per $1500 \mathrm{~cm}^{3}$ of soil) were $40,759 \pm 36,712,66,048 \pm$ $39,730,9,904 \pm 16,591$ and 9,257 $\pm 17,204$. Root gall rating was also significantly lower $(\mathrm{p} \leq 0.05)$ at the $100 \mathrm{~g}$ and $200 \mathrm{~g}$ chitin levels compared to the control. Percent gall ratings were $3.3 \pm 1.0 \%, 3.2 \pm 1.0 \%, 1.0 \pm 0.5 \%$, and $1.0 \% \pm$ $0.6 \%$ for amendment levels of $0,50,100$, and $200 \mathrm{~g}$ chitin, respectively.
\end{abstract}

Keywords: Ecologic chitin, root knot nematode, tomato plant, agricultural management

\section{Introduction}

Nematodes are roundworms that are found in almost all habitats [1]. Some species, Steinernema, Risbravis, Rhabditis, e.g., are beneficial in decomposition of organic matter and attacking insects and other pests. Beneficial species are usually referred to as free-living nematodes.
Other nematode species are parasitic and harmful to plants, animals, and humans. Soil provides an excellent habitat for nematodes. Thousands of nematodes may inhabit 100 $\mathrm{cm}^{3}$ of soil [2]. Plant-parasitic nematodes may live within plant roots or inhabit the rhizosphere soil around plant roots and root hairs [3]. Endoparasitic nematodes live and feed inside the plant's tissues, while ectoparasitic 
nematodes feed from the plant's root surfaces. It has been reported that a single endoparasitic nematode may kill a plant and reduce productivity while ectoparasitic nematodes feed on a plant without seriously affecting its production [4]. Few plant-parasitic species are host specific and generally have broad host ranges [5].

Common names have arisen from a morphological characteristic of the nematode or from plant damage symptoms resulting from nematode infestation [2]. Ring nematode received its name due to ring-like structures on its surface. Dagger and needle nematodes have very long stylets. Root knot nematodes cause galls or knots to form on roots. The sheath nematode retains the cuticle during molting resulting in the appearance of a sheath surrounding the body. Feeding by stubby root nematode causes the root tip to stop growing and appear stubby. Spiral nematode appears to be curled up when viewed microscopically. Pin nematode is small in size compared to other plant-parasitic nematodes.

Reproductive strategies differ among species. The eggs of root-knot nematodes are extruded in a gelatinous matrix to form the egg mass on the surface of the root (gall) and juveniles hatch as soon as they are fully embryonated. Some nematode eggs are retained within the female body which forms a cyst and remains dormant until stimulated to hatch by root exudates specific to host crops, potato and tomato [6]. Root-knot nematodes may reproduce by mitotic parthenogenesis or by sexual means and have several generations on one crop. Each female can produce up to 2000 eggs per crop. Potato cyst nematodes reproduce sexually. Nematodes are main concerns in the agriculture community. Parasitic populations are dense in warmer climates [1] and light, sandy soils harbor larger densities [7]. Longer growing seasons and long feeding periods increase reproductive rates and potentially as many as ten generations of nematodes may be produced in one growing season. Root-feeding nematodes are opportunistic. They are early invaders of agricultural environments. Plant-parasitic nematodes increase when the same host crop is planted every year. The food web changes after yearly cultivation of soil and reduces organisms that prey on nematodes. Soil must be actively managed to prevent nematode infestations. Crops may sustain indirect damage due to openings in plant tissues that provide entry of harmful fungi and bacteria [8].

Traditional nematode control involves the use of soil fumigants. The most common gas fumigant for insects, termites, rodents, weeds and nematodes on agricultural commodities is methyl bromide [9]. Methyl bromide is a broadly used soil fumigant $[10,11]$. It is widely used with commercial fruit and vegetable crops $[12,13]$. In 1993, methyl bromide was listed as an ozone-depleting compound. This fumigant was placed under the U.S. Clean Air Act of 1990. The domestic production of the compound was frozen in 1994 to 1991 levels [14]. Reports indicate that methyl bromide is highly toxic [15]. Methyl bromide is poisonous if absorbed by skin contact or swallowed [16]. Repeat exposure may cause allergic disorders, systemic effects, kidney injury, upper respiratory tract damage and central nervous system depression [17]. Additionally, the EPA also has concerns of methyl bromide's potential to destroy ozone $[18,19]$.

Sustainable control of nematodes and inhibition of damage to agriculture involves integration of preventive measures. Crop rotations, soil solarization and biological controls are some methods currently researched [20-29]. Sustainable methods must follow criteria for selected use. They must be economical, easy to use and effective. There is a delicate balance between soil, microorganisms and organic matter to support populations. Nematode control has to sustain ecosystem stability. The following research evaluates the effects of Ecologic soil amendment on the root knot nematode, Meloidogyne incognita and growth of tomato, Lycopersicon esculentum as a biological, sustainable nematode management agent.

Effective control of plant-parasitic nematodes and other soil borne plant pathogens is a serious challenge for crop producers in the United States and in many countries throughout the world. Bans on traditional pesticides make it necessary to research alternative methods of controlling nematodes on plants and in soils. Remedies must have viable and cost efficient strategies based on researched recommendations. No single synthetic chemical or nonchemical substance is totally effective in prevention of plantparasitic nematode diseases. New studies are needed to test biological options. Substances must be available for use in greenhouses and in the field for production of vegetables, such as tomatoes, lettuce, strawberries, cucumbers and sweet peppers as well as ornamental plants including cut flowers.

Because amendments to soils may pose leachate problems, biological or naturally occurring substances may be favorable over the use of chemicals. While some materials have been studied for growth effects and nematicidal properties, more research must be done on newly developed products. Many naturally occurring substances help reduce cost over traditional chemical methods [30]. The present research was designed to assess the potential of Ecologic as a tool for agricultural management of root knot nematode, and to evaluate its effect on the growth of tomato plant.

\section{Materials and Methods}

\section{Experimental Design}

In the current study, greenhouse experiments were conducted during which, tomato seeds (Lycopersicon esculentum Mill., 'Floradel') were planted in pots using soil that has been sterilized by autoclaving using Autoclave Sterilmatic (Model STM-E 208 240Volts12 K.W Forge). The experimental design was a randomized complete block design with four blocks, 0, 50, 100 and $200 \mathrm{~g}$ Ecologic chitin per $1500 \mathrm{~g}$ soil v/v. Five replications were used.

\section{Plant Establishment and Maintenance}

Floradel seeds, L. esculentum, were planted in starter pots. The pots were obtained from Mississippi State 
University Entomology and Plant Pathology Department, Starkville, MS. Soil was amended with Ecologic chitin material, obtained from Ecologic Company, Bayou La Batre, Alabama. The Ecologic material was added according to the following amounts: $50 \mathrm{~g}, 100 \mathrm{~g}$ and $200 \mathrm{~g}$ per $1500 \mathrm{~g}\left(\mathrm{~cm}^{3}\right)$ soil v/v, to a zip lock bag mixed with Freestone fine sandy loam, autoclaved soil, obtained from Mississippi State University field, Starkville, Mississippi, filling each pot. No chitin material was added to the controls. A two-week wait period preceded planting to allow the chitin material to breakdown into the soil. After germination, the two-week old plant seedlings were transplanted into $1500 \mathrm{~g}$ size clay pots, one plant per pot. The tomato roots were inoculated using $10-100 \mu \mathrm{l}$ pipets with 5,000 root knot eggs per $1500 \mathrm{~g}$ chitin/soil material. The nematode eggs were obtained from The Mississippi State University, Entomology and Plant Pathology Department. Egg extraction is described below. Plants were maintained under greenhouse conditions at temperatures ranging between $26^{\circ}$ and $33^{\circ} \mathrm{C}$ and irrigated as needed.

The plants were harvested after 45 days of cultivation. Soil was loosened in each pot by soaking pots with $400 \mathrm{ml}$ to $600 \mathrm{ml}$ of water. The above the soil level shoot plant material was cut and placed on marked brown paper. A metal spatula was used to loosen soil with plant root material from the pot. The soil with plant root material was placed into a gallon bucket. Enough water was added slowly and gently to this bucket to cover half the soil material to loosen roots and plant material from the soil. The soil was gently worked from the root material. The bucket with soil and water was set aside for later juvenile egg extraction.

\section{Nematode Extraction and Examination}

To begin the nematode extraction, roots were placed into a beaker with enough $10 \%$ chlorine bleach solution to cover the roots. The roots were agitated for $3.5 \mathrm{~min}$ by stirring with a scapula in the $10 \%$ chlorine bleach solution. After $3.5 \mathrm{~min}$, the roots were removed from the beaker and placed on marked brown paper to be weighed. The $10 \%$ chlorine bleach/nematode extract was poured from the beaker and sieved through a 200 mesh sieve nested on top of a 500 mesh sieve. (Sieve: No. 200, USA standard test sieve. Fisher scientific Company, 75 micrometers. Sieve: No. 500. USA standard test sieve. Fisher Scientific Company, 25 micrometers). The roots were rinsed with water over the 200 mesh sieve and placed back on the marked brown paper. With a wash bottle, the 500 mesh extraction was rinsed with water after a total volume of $40 \mathrm{ml}$ into a $150 \mathrm{ml}$ beaker. Nematodes were counted on a grated petri dish under the Olympus BH2 B071 microscope (Japan Model C35AD-4) at 40X magnification.

\section{Juvenile and Egg Extraction}

Soil and water contents from the bucket set aside as described above (bucket 1 ) were poured over a 60 mesh sieve into bucket 2. The contents of bucket 2 were sieved over the sink using a 325 mesh sieve. (Sieve No. 60, USA standard test sieve. Fisher Scientific Company, 250 micrometers. Sieve No. 325, USA standard test sieve, 45 micrometers. Fisher Scientific Company, USA.) Repeat rinsing was done over the 325 mesh sieve with a gentle stream of water until $20 \mathrm{ml}$ soil or less remained on bottom of the 325 mesh sieve. A 30-40 ml juvenile egg extract was collected by washing the 325 mesh sieve extract into a 150 $\mathrm{ml}$ beaker. The beaker content was allowed to settle for 2 hours. After 2 hours, water was discarded. A timer was set to 10 minutes. A $1.3 \mathrm{M}$ sucrose solution was added to the bottom layer contents of the beaker to give a $50 \mathrm{ml}$ volume and gently swirled. The sugar-nematode suspension was decanted into $50 \mathrm{ml}$ centrifuge tube and centrifuged for 1 min at $1500 \mathrm{rpm}$ using a centrifuge from International Equipment Company (Model 120 Size 2 50/60 Hertz, 7.3 amps). After centrifugation, the supernatant was poured off onto a 500 mesh sieve held over the sink. The pellet soil layer of the centrifuge tube was discarded. The extract was rinsed under a very gentle stream of running water to rinse off the $1.3 \mathrm{M}$ sucrose solution, and collected into a $150 \mathrm{ml}$ beaker. Water was added to bring the J2 egg extraction to $40 \mathrm{ml}$ volume. Examination and counting of eggs and juveniles on grated Petri dishes were done using the Olympus BH2 B071 microscope (Japan Model C35AD-4) at $40 \mathrm{X}$ magnification.

\section{Fresh and Dry Plant Weights}

Fresh weights of both shoot material (stems and leaves) and root material for each plant were taken using Model N02120 Ohaus digital balance. For dry weight, the plant shoot and root materials were placed in separate brown paper bags and marked separately for each plant. The bags containing shoot and root materials were then placed into the Precision Scientific drying oven (115 volts, 2.6 amps), $100^{\circ} \mathrm{C}$ for 3 days. Dry weights were recorded using Model N02120 Ohaus digital balance.

\section{Root Gall Rating}

The roots were examined for galling and rated according to the following method. Each group of root plant materials for the $0 \mathrm{~g}$ chitin control, $50 \mathrm{~g}$ chitin, $100 \mathrm{~g}$ chitin and $200 \mathrm{~g}$ chitin amendments were laid on the lab counter top and observed for root knot galls. Root galling was recorded on a scale as follows: $0=$ no galling, $1=$ $25 \%$ galling, $2=50 \%$ galling, $3=75 \%$ and $4=100 \%$ galling.

\section{Statistical Analysis}

The data were analyzed for comparison of means. The plant materials were tested for significant differences in fresh and dry biomass, using Dunnett's multiple comparison tests. The significance was considered at $\mathrm{p} \leq$ 0.05. Analysis was performed using SAS. Charts were created in EXCEL. 


\section{Results}

\section{Plant Growth}

Figure 1 shows the effect of chitin amendment on the growth (shoot, root and total biomass fresh weight) of $L$. esculentum. High and low shoot fresh weights (g) for amended soil plants were: $101.9 \mathrm{~g}$ and $35.9 \mathrm{~g}$ for $50 \mathrm{~g}$ chitin, $118.4 \mathrm{~g}$ and $35.0 \mathrm{~g}$ for $100 \mathrm{~g}$ chitin, and; 129.8 and $19 \mathrm{~g}$ for $200 \mathrm{~g}$ chitin. Significant differences were observed in the shoot biomass of L. esculentum at the 100 g chitin concentration when compared to the control. The total biomass fresh weight average was higher at the $100 \mathrm{~g}$ chitin concentration ( $\mathrm{p} \leq 0.05$ ). Shoot fresh weight at $100 \mathrm{~g}$ chitin level showed a significant increase when compared to the control $(\mathrm{p} \leq 0.05)$. Root biomass fresh weight of $L$. esculentum indicated no significant differences compared to the plants grown in the control soil. The total plant biomass fresh weight indicated highest weight at $100 \mathrm{~g}$ chitin amendment.

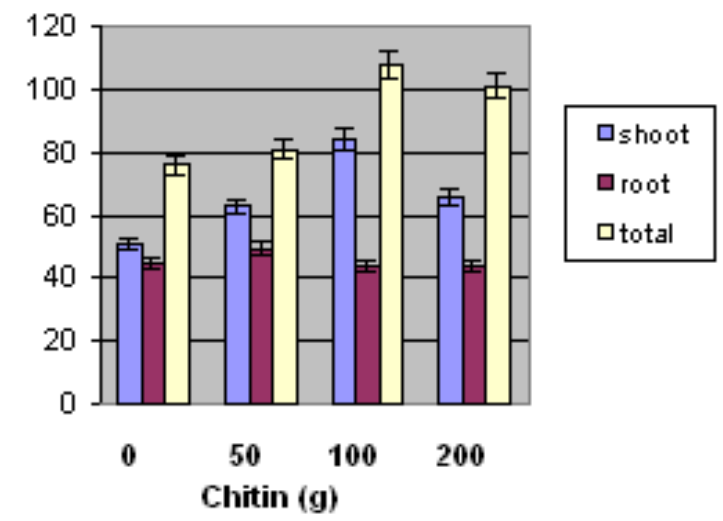

Figure 1: Effect of chitin amendment on the fresh weight of 'Floradel' tomato plant (L. esculentum). Data points represent means \pm SDs. $\mathrm{N}=10$.

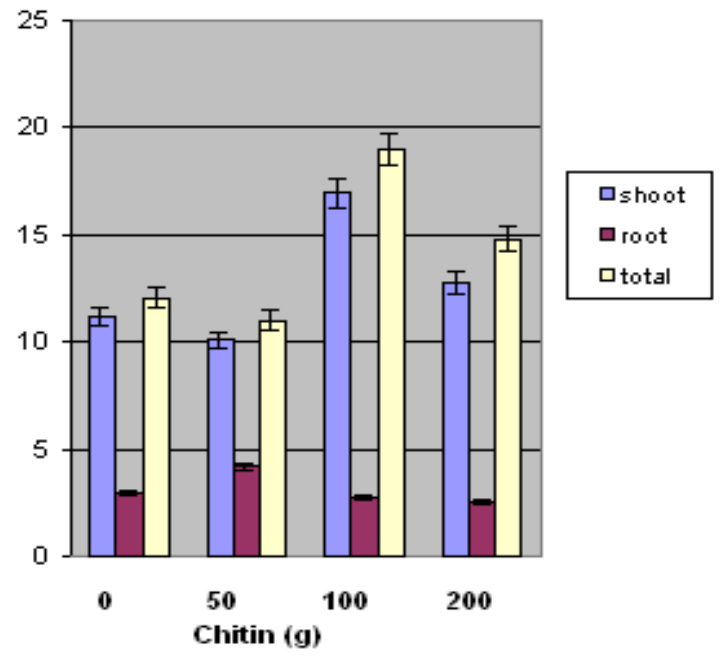

Figure 2: Effect of chitin amendment on the dry weight of 'Floradel' tomato plant (L. esculentum). Data points represent means \pm SDs. $\mathrm{N}=10$.
Figure 2 shows the effect of Ecologic chitin amendment on the growth of $L$. esculentum, based on the dry weights of shoot and root materials and of total biomass. High and low shoot dry weights (g) for amended soil plants were: $19.4 \mathrm{~g}$ and $4.1 \mathrm{~g}$ for $50 \mathrm{~g}$ chitin, 23.9 grams and 8.0 grams for $100 \mathrm{~g}$ chitin, and 23.4 and $4.0 \mathrm{~g}$ for $200 \mathrm{~g}$ chitin. Significant differences were observed in the shoot biomass dry weight of L. esculentum at the $100 \mathrm{~g}$ chitin concentration level when compared to the control plant materials. The average dry weight of the shoot biomass was significantly higher $(\mathrm{p} \leq 0.05)$ at the $100 \mathrm{~g}$ chitin concentration.

\section{Nematode Development}

Figure 3 shows the effect of chitin amendment on nematode eggs. High and low values of eggs on plants grown in amended soil were as follows: $50 \mathrm{~g}$ chitin 162,225 and 16,223 eggs/1500 $\mathrm{cm}^{3}$ soil; $100 \mathrm{~g}$ chitin 54,075 and 0 eggs/1500 $\mathrm{cm}^{3}$ soil; $200 \mathrm{~g}$ chitin - 54,620 and 0 eggs $/ 1500 \mathrm{~cm}^{3}$ soil. The highest $M$. incognita egg count was observed at the $50 \mathrm{~g}$ Ecologic chitin level. Significantly low values were observed at $100 \mathrm{~g}$ and $200 \mathrm{~g}$ chitin levels compared to the control plant. However, the average number of eggs was higher at $50 \mathrm{~g}$ chitin compared to the control.

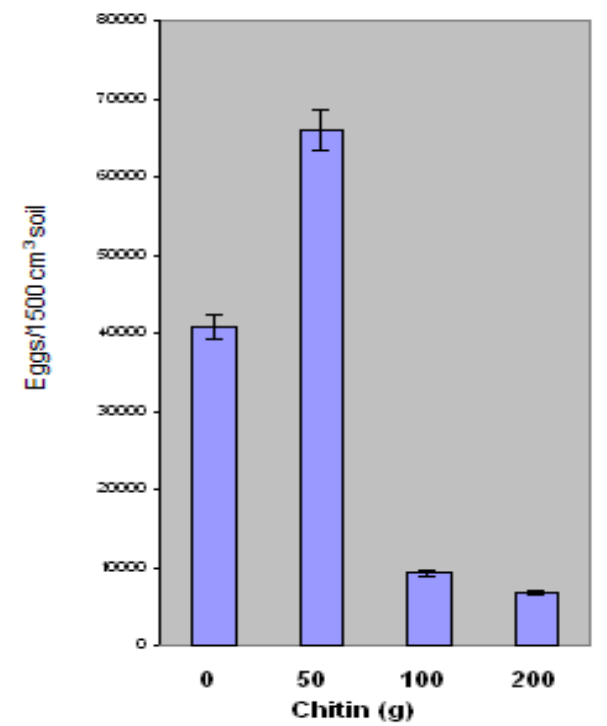

Figure 3: Effect of chitin amendment on the concentration of root knot nematode ( $M$. incognita) eggs on 'Floradel' tomato plant (L. esculentum). Data points represent means \pm SDs. $\mathrm{N}=10$.

Figure 4 illustrates the effect of chitin amendment on juvenile (J2) counts. Maximum and minimum numbers of juveniles on plants amended with chitin were as follows: $50 \mathrm{~g}$ chitin - 139,050 and 50,985 J2/1500 $\mathrm{cm}^{3}$ soil; $100 \mathrm{~g}$ chitin - 258 and $0 \mathrm{~J} 2 / 1500 \mathrm{~cm}^{3}$ soil; $200 \mathrm{~g}$ chitin - 258 and $0 \mathrm{~J} 2 / 1500 \mathrm{~cm}^{3}$ soil. Similar to the test with eggs, amended plants showed greater J2 counts of M. incognita at the $50 \mathrm{~g}$ 
Ecologic chitin level. J2 populations significantly decreased $100 \mathrm{~g}$ and $200 \mathrm{~g}$ chitin levels, as compared to the control plants. The average number of $\mathrm{J} 2$ was higher at 50 $\mathrm{g}$ chitin and lower at both $100 \mathrm{~g}$ and $200 \mathrm{~g}$ chitin concentrations compared to the control.

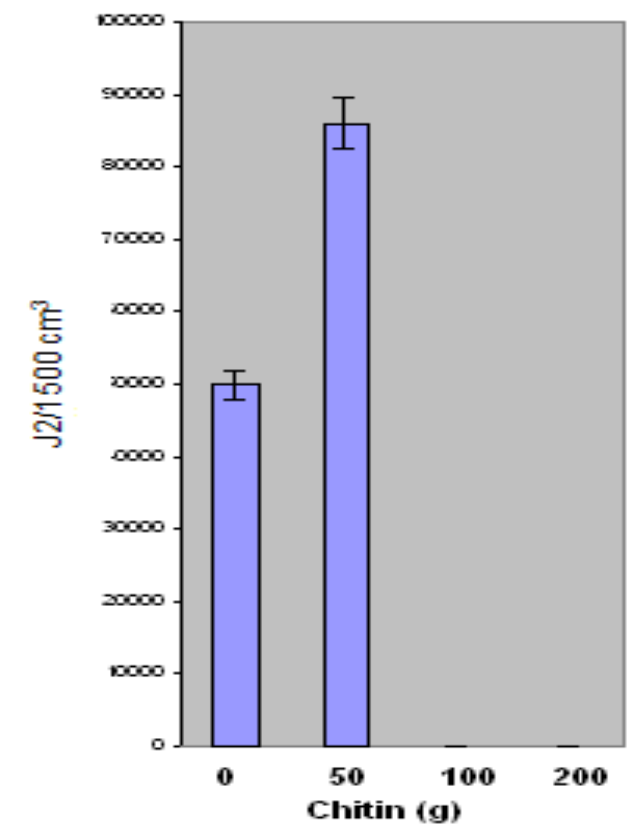

Figure 4: Effect of chitin amendment on the concentration of root knot nematode ( $M$. incognita) juveniles on 'Floradel' tomato plant (L. esculentum). Data points represent means \pm SDs. $\mathrm{N}=10$.

Root gall rating of $M$. incognita indicated highly significant differences at $100 \mathrm{~g}$ and $200 \mathrm{~g}$ chitin levels compared to the control plants. No statistically significant difference was obtained in gall rating between control and the $50 \mathrm{~g}$ chitin amended plants (Figure 5).

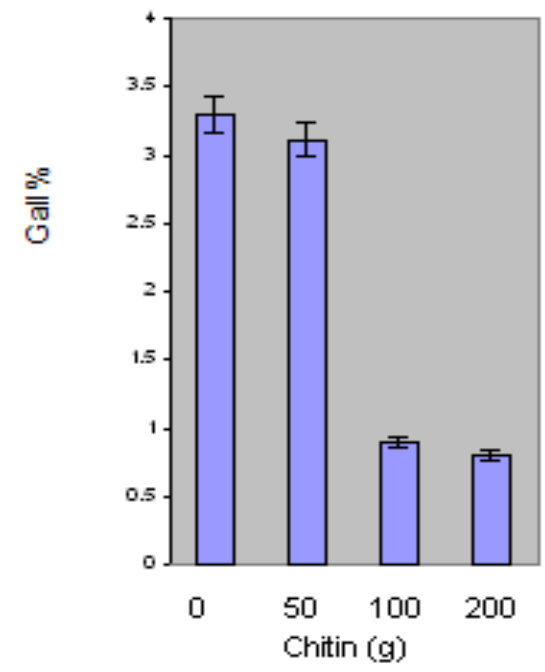

Figure 5: Effect of chitin amendment on gall rating of tomato plant in the presence of $M$. incognita nematodes. Data points represent means \pm SDs, $N=10$. $\mathrm{p} \leq 0.05$.

\section{Discussion}

Findings of this present research are consistent with results of similar studies using chitin-containing products to manage nematodes in vegetable plants. Previous studies have indicated that the nematicidal effect of chitin may be partially due to nematode toxicity and partly due to the stimulation of nematode-parasitic fungi with chitinolytic properties that manipulate microflora populations and induce desired changes in nematode populations. Studies conducted by Baron and Thorne have reported some positive effects associated with the use of biological shell meal to control nematode infestation in vegetables [31].

Results of the present research suggest that Floradel tomato plants grown in Ecologic chitin-amended soil demonstrate a significant reduction in knot nematode ( $M$. incognita) eggs and juvenile populations at $100 \mathrm{~g}$ and 200 $\mathrm{g}$ chitin levels. However, an increase in populations was found with the $50 \mathrm{~g}$ chitin level. Similar research examined a chitin-protein product on plant growth and nematode control. Clandosan was compared with isazofos (Miral 3G) and methyl bromide for the control of $M$. incognita in the tobacco industry. Root-knot infestation stunted all untreated plants and reduced leaf production as well as net yield of cured leaves. Leaf quality was not affected. While methyl bromide was the most effective against nematode infestation, chitin-protein and isazofos were equally effective in reducing the number of root galls to low numbers [32]. The results showed a positive influence of Clandosan on development of the plants in all of the three levels of infestation. Unlike, the present research findings, no effect was induced on nematode population in the soil and on the gall index of the roots, both appearing similar to those observed in the untreated plants.

A study of nematode management on vegetables was conducted using mixtures of soybean meal (SBM), urea and a chitinous material (Clandosan 601) derived from blue crab (Callinectes sapidus) wastes for control of Meloidogyne arenaria. The study was conducted under greenhouse conditions. Root galls were evaluated upon treatment. Soil amendments containing 2-4 g SBM/kg of soil were most effective in reducing galls caused by $M$. arenaria in squash (Cucurbita pepo) roots when SBM was added to soil together with $1 \mathrm{~g}$ of Clandosan 601 and $0.5 \mathrm{~g}$ urea $/ \mathrm{kg}$ of soil. Soil chitonase activity increased with increasing rates of SBM added to soil and was related inversely to the number of galls/g of fresh squash root. The amendment reduced numbers of $M$. incognita in 'Jewel' sweet potato (Ipomoea batatas) but did not increase yield (Rodriguez-Kabana et. al 1990). Root gall ratings were significantly lower $(\mathrm{p} \leq 0.05)$ in the present study in response to $100 \mathrm{~g}$ and $200 \mathrm{~g}$ Ecologic chitin amendment.

Results of J2 experiments were consistent with other research findings involving nematode species reproduction. Chen and collaborators have reported that biological control appears to be a promising strategy that can be integrated into a management program to reduce the nematode population and minimize yield loss [33]. Their research has focused on the determination of the impact of 
fungal antagonists on nematode populations. Fungi that were frequently encountered in cysts, females, and/or eggs were tested for their pathogenicity to the nematode eggs. In the present research, root-knot eggs and J2 population numbers were significantly lower at 100 and $200 \mathrm{~g}$ chitin treatment. Further study is needed to determine exact mechanism of nematode suppression. Toxicity may have affected biomass at the 100 gram and 200 gram chitin levels. As a result, shoot and root plant materials were lower at these levels.

Methyl bromide is the major soil fumigant in use worldwide [34]. However, due to its role in depletion of the ozone layer, international agreement has been reached calling for its reduced consumption and complete phasing. Nonchemical methods and strategies include cultural methods, crop rotation, intracropping, cover crops (and antagonistic plants), soil amendments, fallow or grass fallows (weed-free), timing of planting/harvesting, farm hygiene and general culture, weed-host control, chemical nematicides, biological, including engineered organisms, physical tillage, including residual root destruction, solarization and flooding to suppress nematode populations [35]. Environmentally sound, sustainable suppression of the root knot nematode is desirable. Results from this study indicate that Ecologic chitin material is an effective biological control agent in reducing the number of juvenile populations and eggs in 'Floradel' tomatoes, $L$. esculentum, at $100 \mathrm{~g}$ and $200 \mathrm{~g}$ chitin levels. Further investigation is required to determine specific mechanisms of nematicidal toxicity at higher levels of treatment.

Acknowledgments: This research was supported by a grant from the United States Department of Education Title III Graduate Education Program at Jackson State University.

\section{References}

1. Dropkin, H.: Introduction to Plant Nematology. John Wiley and Sons. New York, New York, 1980, 38-44, 242-246, 256.

2. Maggenti, A. R.: General Nematology. Springer: New York, 1981, 1- 372.

3. Agrios, G. N.: Plant Pathology. Academic Press. New York, 1969, 1-629.

4. Ingham, R. E.; Trofymow, J. A.; Ingham, E. R.; Coleman, D. C.: Interactions of bacteria, fungi and their nematode grazers: effects on nutrient cycling and plant growth. Ecol., 1985, 55:119-140.

5. Yeates, G. W.; DeGoede, T. R.; Bongers, D. Freckman, and S.S. Georgieve. Feeding habitats in soil nematode families and genera-an outline for soil ecologists. J. of Nematol, 1993, 25:315-331.

6. Ehwaeti, M.; Elliot, M.; McNicol, M.; Trudgill, D.: Modeling nematode population growth and damage. Crop Protection, 2000, 19:739-745.

7. Yepsen, B.: The encyclopedia of Natural Insect and Disease Control. Rodale Press. Emmaus, PA., 1984, 267-271.
8. McKenry, M. V.; Roberts. P. A.: Phytonematology Study Guide. University of California, 1985.

9. Braun, A. L.; Supkof, D. M.: Options to methyl bromide for the control of soil borne diseases and pests. Pest Management Analysis and Planning Program, California Department of Pest Regulation, 1994.

10. Alexeef, G.; Kilgotr, W. W.: Methyl Bromide Residue Review document, 1994, 88. 101-153.

11. Gilreath, James; Jones, P.; John, M.; Bielinski, S.; Amegda, J.; Overman, M.: Soil fumigant evaluations for soilborne pest and Cyperus rotundus control in fresh market tomato. Crop Protection, 2004, 1:1-3.

12. Hancock, James F.; Callow, Peter W.; Serce, Sedat; Schilder, Annemiek C.: Relative Performance of Strawberry Cultivars and native hybrids on fumigated and Nonfumigated soil in Michigan. Hortscience, 2001, 356:1:136- 138.

13. Hunter, Beatrice: Methyl bromide ozone depletion compound. Consumer Res. Magazine, 1999, 1:23.

14. EPA. Protect yourself from pesticide. Guide for Agriculture Workers, 1994.

15. Environmental Working Group. Pesticide Use Report, California EPA Department of Pesticide Regulation, 1995.

16. Lu, F. C.: A review of the acceptable daily intakes of pesticides assessed by the World Health Organization. Toxicol. and Pharmacol., 1995, 21:351- 364.

17. Wauchope, R. D.; Butler, T. M.; Hornsby; A. G.; Beckers, P. W.; Augustine, B.; Burt, J. P.: Pesticide properties database for environmental decision making. Review of environmental contaminants. Toxicol., 1992., 123:1-157. 10-12.

18. Butler, J. H.: Methyl bromide under scrutiny. Nature, 1995, 376:469-470.

19. Gamliel, A.; Katan, J.: Suppression of major and minor pathogens by fluorescent pseudomonads in solarized and non-solarized Soil. Phytopathol., 1993, 83:68-75.

20. Gamliel, A.; Stapleton, J. J.: Characterization of antifungal volatile compounds evolved from solarized soil amended with cabbage residues. Phytopathol, 1993, 83:899-905.

21. Gamliel, A.; Stapleton, J. J.: Effect of chicken compost or ammonium phosphate and solarization on pathogen control, rhizosphere microorganisms, and lettuce growth. Plant Dis., 1993, 77:886-891.

22. Hartz, T. K.; deVay, J. E.; Elmore, C. L.: Solarization is an effective soil disinfestations technique for strawberry production. HortSci., 1993, 28:104-106.

23. Maggenti, A. R.: General Nematology. Spriner: New York, 1981, 1- 372.

24. Ramirez-Villapudua, J.; Munnecke, D. E.: Effect of solar heating and soil amendments of cruciferous residues on Fusrium oxysporum and other organisms. Phytopathol, 1988, 28:289-295.

25. McSorley, R.; Gallaher, R. N.: Managing plant parasitic nematodes in crop sequences. Soil and Crop Science Society of Florida Proceedings, 1991, 51:42-45. 
26. Csinos, A. S.; Summer, D. R.; Johnson, W. C.; Johnson, R. M.; Johnson, A. W.; McPherson, A. W.; Dowler, C. C.: Methyl bromide alternatives in tobacco, tomato and pepper transplant production. Crop Protection, 2000, 19:1:139-149.

27. Ko, M. P.; Schmitt, D. P.: Changes in plant-parasitic nematode populations in pineapple fields following intercycle cover crops. J. of Nematol., 1996, 28(4): 546-556.

28. McSorley, R.; Dickson, D. W.; Debrito, J. A.; Hochmuth, R. C.: Tropical rotation crops influence nematode densities and vegetable yields. $J$. of Nematol., 1994, 26(3): 308-314.

29. Reed, Jack; Randall, T.; Luttrell, G.; Scott, D.; Stewart, H.; Bowden, F.; Royce, O.; Randle, Parker, F.; Charles. D.: Development of sustainable, costefficient strategies for managing cotton insects - an interim report. Mississippi State University, 1999.
30. Baron, G.; Thorne, R. G.: Destruction of nematodes species of Pleurotus. Canadian J. of Botany, 1978, 65:774-778.

31. Yuen, P. M.; Shokri, A.: Comparison of chitin-protein, isazofos and methyl bromide in the control of Meloidogyne incognita on tobacco. MARDI Research Journal. 1994, 22:57-72.

32. Chen, S.; Chen, F.; Xingzhong, L.: Impact of fungal antagonists on SCN - A Minnesota Perspective. University of Minnesota Southern Experiment Station Publication, 1998.

33. Chellemi, D. O.: Agricultural Research Service, U.S. Horticultural Research Laboratory, U. S. Department of Agriculture. Phytopathol., 2002, 92:12: 1367- 1372.

34. Sherf, A.; MacNab, A. A.: Vegetable Diseases and their Control. 2nd ed. Wiley \& Sons, New York, 1986. 